\title{
PRELIMINARY STUDY ON RELAP5 SIMULATION OF DVI LINE BREAK ACCIDENT IN THE ATLAS FACILITY USING BEST ESTIMATE PLUS UNCERTAINTY METHOD
}

\author{
Andi Sofrany Ekariansyah, Surip Widodo \\ Center for Nuclear Reactor Technology and Safety-BATAN \\ Puspiptek Area, Setu, Tangerang Selatan, 15310 \\ Email: andi_se@batan.go.id \\ Diterima editor: 23 Januari 2017 \\ Diperbaiki: biarkan 23 Februari 2017 \\ Disetujui untuk publikasi: 27 Februari 2017
}

\begin{abstract}
PRELIMINARY STUDY ON RELAP5 SIMULATION OF DVI LINE BREAK ACCIDENT IN THE ATLAS FACILITY USING BEST ESTIMATE PLUS UNCERTAINTY METHOD. The Best Estimate plus Uncertainty (BEPU) is a methodology, which was introduced in the deterministic safety analysis to evaluate limitations of codes in simulating realistic plant behavior by providing quantified uncertainty bands of calculation results. It has been already widely accepted in licensing nuclear power plant by regulatory bodies of United States (USNRC), Argentina, and Canada. The uncertainty evaluation in the BEPU method is performed by different approaches such as GRS, IRSN, ENUSA, AEAT, and UNIPI. Due to the complexity of other approaches, the purpose of this study is to present some key aspects of the BEPU process using the GRS methodology by selecting the ATLAS test facility to simulate $50 \%$ break of DVI line since any safety analysis performed so far was using deterministic best estimate approach only. As comparison of the best estimate simulation performed by RELAP5/SCDAP/Mod3.4, experimental data related to the event was used. After 100 simulations, the uncertainty bands of peak heater of clad temperature and primary pressure transient obtained were only in a close agreement with the experimental data in the earlier period and less than 250 seconds during the transient condition. Therefore the overall accuracy of the best estimate simulation plays a key role on the final results of the uncertainty analysis because the propagation of any discrepancy in the best estimate with the experimental data will occur throughout the simulation. After that, selecting the important parameters to be randomly generated needs to be performed carefully by studying the important phenomena related to the event analyzed and associated plant model.
\end{abstract}

Keywords: best estimate plus uncertainty, DVI line break, ATLAS facility, RELAP5, simulation 


\section{INTRODUCTION}

The safety of nuclear power plant operation relies on whether the real operating parameters are still between the limiting values that representing a safety margin. Beyond the lower or upper limiting values, there are conditions in which the barrier against radioactivity release would fail [1]. Typically, safety margins are determined by using computational tools for safety analysis, and advanced best estimate computer codes are preferred as also have been required by IAEA Safety Guide [2]. The best estimate (BE) codes have been developed to replace the conservative approach that used in the earlier period of conducting safety analysis in nuclear power plant. Due to the limitation of the conservatism in the practical way to prove, a BE approach was introduced in order to evaluate the plant behavior as realistic as possible with its own limitations, which lead to the concept of uncertainties. Uncertainty evaluation will provide a quantitative picture due to the use of different BE codes and the insufficient knowledge of the phenomena, in the form of quantified uncertainty band of calculation results [3]. From the above description, the concept of Best Estimate Plus Uncertainty (BEPU) methodology was introduced and begun to be standardized in 1990 by the USNRC in order to be acceptable in licensing and regulatory activities. In addition to the BEPU developed by USNRC, the BEPU approach to licensing and regulation has also been used in other countries with various methodologies, even though their components are similar with the USNRC approach [4]. Several examples of the BEPU methodologies have been applied during the licensing process of the Atucha II PHWR for completing the Chapter 15 of Final Safety Analysis Report (FSAR) [5, 6] and during a safety analysis for obtaining a better characterization of safety margins in the Pickering B CANDU reactor [7].

Due to the different BEPU methods, a programme called the BEMUSE (Best Estimate Methods - Uncertainty and Sensivity Evaluation) was launched in 2003 by the committe on the safety of nuclear installations (CSNI) with the aim of achieving a deeper understanding of the methods, developing common understanding, and promoting their use by the regulator bodies and industry. One of the BEMUSE programme purposes is an assessment of each BEPU methodology by comparing it with available experimental data for certain scenario [8]. The activity consists of two main steps described in 6 phase reports, which are best estimate and uncertainty evaluation on the L2-5 Experiment of the LOFT (Loss of Flow Test) Facility (Phases Report I, II, and III) and best estimate, sensitivity studies, and uncertainty evaluation for a Large Break LOCA in Zion nuclear power plant (Phases Report IV, V, VI). From the 6 phase activities, the Phase III and V result provides a detail description on how an uncertainty analysis following the best estimate analysis might be followed as a part of safety analysis $[9,10]$. Before the launching of BEMUSE programme, there were several uncertainty methodologies developed by different institutions. The first uncertainty analysis used to support licensing process was the CSAU (code scaling, applicability and uncertainty) methodology that was developed by the USNRC in 1988 [11]. In 1985, Gessellschaft fur Anlagen und Reactor Sicherheits (GRS) in Germany proposed a probabilistic uncertanty analysis method called the GRS method, which is slightly different with the CSAU method [12]. Other institution, University of Pisa (UNIPI), have started a research on different uncertainty calculation methodology, the UMAE (uncertainty methodology based on accuracy extrapolation), which is then integrated into a code to become an 'automatic' method, the CIAU (code with the capability of internal assessment of uncertainty) [13]. In order to gain insights into differences of the uncertainty methodologies, the Committee on the Safety of Nuclear Installations (CSNI) performed an Uncertainty Methods Study (UMS) from 1995 to 1997, which is followed by 5 organizations along with their methods: GRS, IRSN, and ENUSA (3 comparable GRS method), AEAT (1 deterministic method), and UNIPI (UMAE method) [14]. From the 3 main methods, the CSAU and GRS were often considered in the application of the BEPU analysis for licensing or for other research activities. Due to the complexity of the CSAU method, the GRS has been selected as the uncertainty method used in this research. This method is also mainly used in the Phase III BEMUSE programme. One application of the GRS uncertainty method can be found in the thermal-hydraulic analysis at the ROSA facility [15].

The purpose of this study is to present some key aspects of the BEPU process using the GRS methodology by selecting the ATLAS (Advanced Thermal-Hydraulic Test Loop for 
Accident Simulation) test facility to simulate one of initiating event. Until now, any safety analysis conducted has been performed using deterministic best estimate approach only when the model nodalization was developed as close as possible with the real nuclear power plant and the results to evaluate the safety criteria also were compared with the best estimate simulation using different code. Such best estimate analyses can be found in several scientific papers related to the AP1000 nuclear power plant $[16,17]$ without considering uncertainty arising during modelling and simulation. The ATLAS test facility is selected due to the availability of the experimental results and related analysis is needed to validate the best estimate simulation. The computational tool used for the BEPU analysis is RELAP5/SCDAP/Mod3.4 as the best estimate code already validated worldwide. The BEPU approach requires an additional computational tool to calculate uncertainty parameter in relation to the GRS method. In this study, the computational tool to generate samples of uncertainty parameter as required by the GRS method is the Microsoft EXCEL. Methodology explaining the procedures of the BEPU analysis and the safety criteria selected as the representation of the results will be further described in the other section of this paper.

\section{THEORY}

\section{GRS Uncertainty approach}

Uncertainty analysis requires an identification and quantification of all important parameters, which are considered uncertain. These potential important parameters will be described by ranges and probability distributions. The approach proposed by GRS is related to the statistical techniques. Uncertainty on computer code results will be solved by a number of code runs. On each code run, all uncertain parameters are varied simultaneously. In the GRS method, the number of code runs do not depend on the number of uncertain parameters, but they depend on the required probability content and confidence level of the statistical tolerance limits. That is where the statistical tools are used to quantify the effect of result variations. The required number of these code runs is determined by Wilk's formula, in which a maximum response with a $95 \%$ confidence level and 95 $\%$ probability require at least 59 samples for one-sided statistical tolerance limit and 93 samples for two-sided statistical tolerance limit [12]. Figure 1 shows the simplified description of the uncertainty analysis using the GRS method.

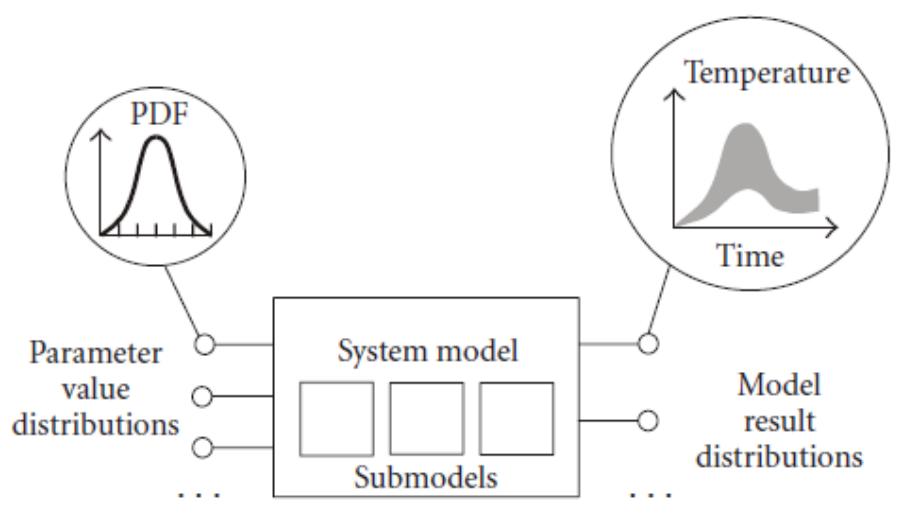

Figure 1. Assigment of range distribution on the uncertainty parameters in the GRS method [12]

In Figure 1, the selected input parameter values are associated with their probability distribution functions (PDFs), in which they are used as inputs in the model nodalization of a certain code. A certain number of parameter sample sets based on the Wilk's formula are randomly generated according to the PDF of each input parameter. After that, a number of code runs is performed for pre-determined event scenario to obtain requested output values, for example peak cladding 
temperature. The output values are quantified by their result distributions in the form of the lower and upper limits (lower and upper uncertainty bound) for the two-sided statistical tolerance limit.

\section{ATLAS Test Facility}

In this study, the uncertainty analysis using the GRS method will be applied in the simulation of an event using the ATLAS test facility. The ATLAS is an integrated test facility for advanced Pressurized Water Reactor (PWR) developed by KAERI. This facility was developed by using the Advanced Power Reactor 1400 MWe (APR-1400) and Optimized Power Reactor 1000 MWe (OPR-1000) as reference plants. This study has selected the ATLAS test facility due to the availability of experimental results. One experimental result is described in the NEA/CSNI report. It describes the experiment of $50 \%$ DVI pipe diameter break in the APR-1400 [18]. This size is considered interesting because it belongs to the EPRI requirements, in which the core uncovery should be proven to be prevented using the best-estimate analysis. The report also contains several calculation results using best-estimate codes such as RELAP5/Mod3.3, ATHLET, APROS, CATHARE, TRACE, KORSAR/GP, and MARS. The results on that report can be used mainly for the best-estimate analysis and as results comparison from different codes and model nodalization in the uncertainty analysis performed in this study. Figure 2 shows the schematic configuration of the ATLAS test facility for modelling purpose required in the best estimate analysis.

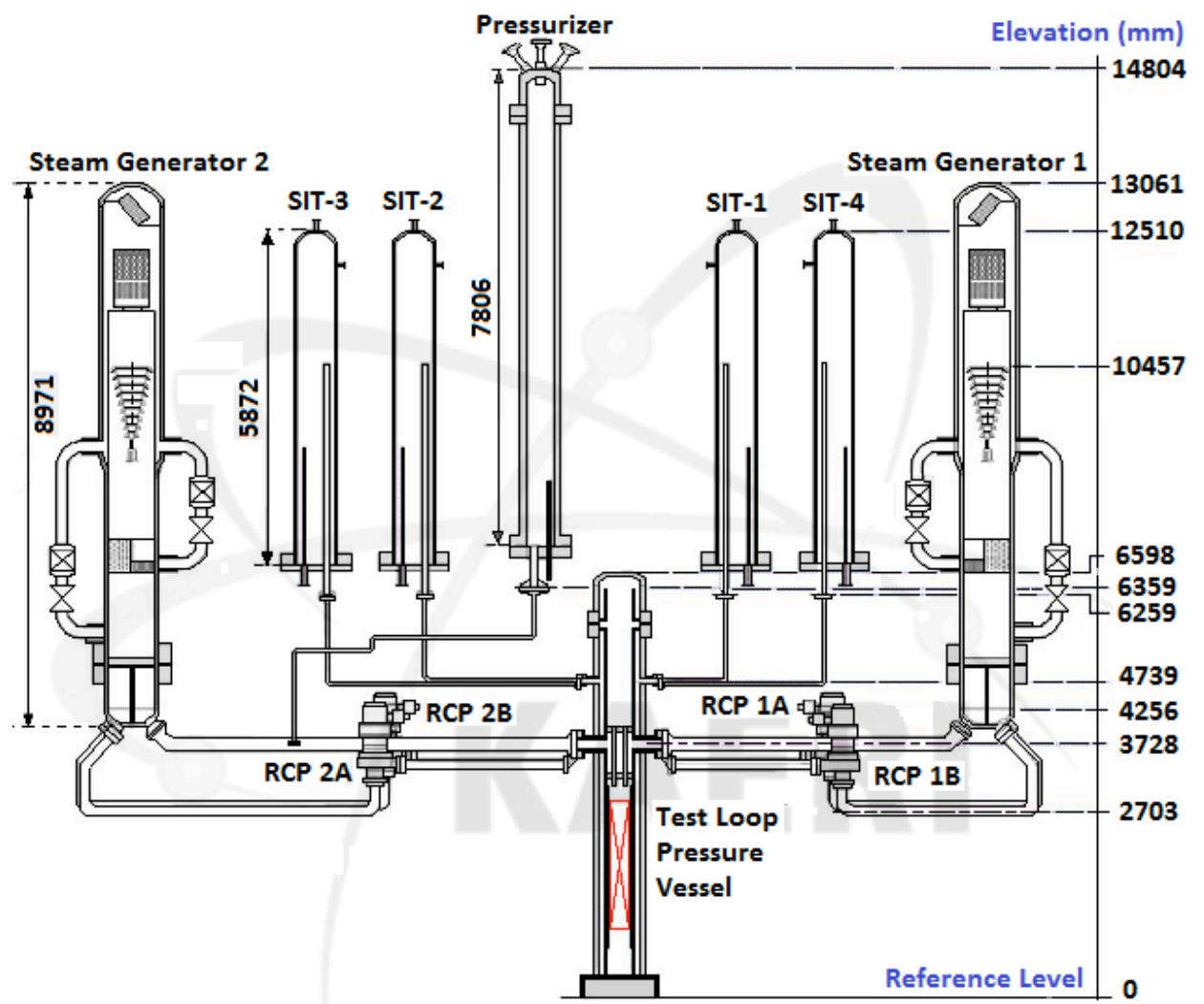

Figure 2. Schematic configuration of the ATLAS facility [19]

\section{METHODOLOGY}

The best estimate and uncertainty analysis in the ATLAS test facility were conducted using RELAP5/SCDAPSIM/Mod3.2 as the computational tool. The uncertainty analysis based on the GRS approach as explained before was described with following step-by-step procedures using the similar code [20]. The first step is selection of scenario. The event to be analysed is $50 \%$ break of 
DVI line with the scenario according to the document [18]. The second step is selection of safety criteria. The $50 \%$ break of DVI line is categorized as a small break LOCA event, which according to the USNRC regulation 10 CFR 50.46 Appendix K, the limits on peak cladding temperature, cladding oxidation, and hydrogen generation must not be exceeded prescribed values [21]. Based on that regulation, peak cladding temperature is selected as safety criteria complemented by system pressure for describing the uncertainty results. The third step is to identify and rank important phenomenas to select potential important parameters achieved using the phenomena and identification ranking table (PIRT) approach for SBLOCA. Each selected important parameters is associated with an appropriate PDF using several references [20, 22]. According to the Wilk's formula, a number of random sampling of selected parameters are generated, which also represent the number of computer runs by RELAP5. For a results distribution with $95 \%$ confidence level and $95 \%$ probability, a minimum number of 93 [22] are required. After the results are obtained, the uncertainty bands are estimated for the peak cladding temperature as selected safety criterion complemented by the system pressure.

\section{RESULTS AND DISCUSSION}

\section{Best estimate simulation for the $50 \%$ break of DVI line event}

The best estimate simulation requires a model nodalization of the ATLAS facility using the RELAP5 code. In the previous research, the ATLAS nodalization and its RELAP5 simulation for the $50 \%$ break on the one of DVI lines have been performed and the results of simulation have been compared with experimental data and other similar analysis [23]. Based on the results, it was required to make modification on the ATLAS nodalization as shown in Figure 3 to gain closer results mainly in time sequence of the event and in the transients of break mass flow, peak cladding temperature, system pressure, core level, and loop seal clearing phenomena. The most distinctive modification is in the division of downcomer from 2 in to 3 annulus components for each loop to accomodate more realistic flowpath and bypass junction and addition of heat structures in the primary and secondary system to simulate heat loss to environment.

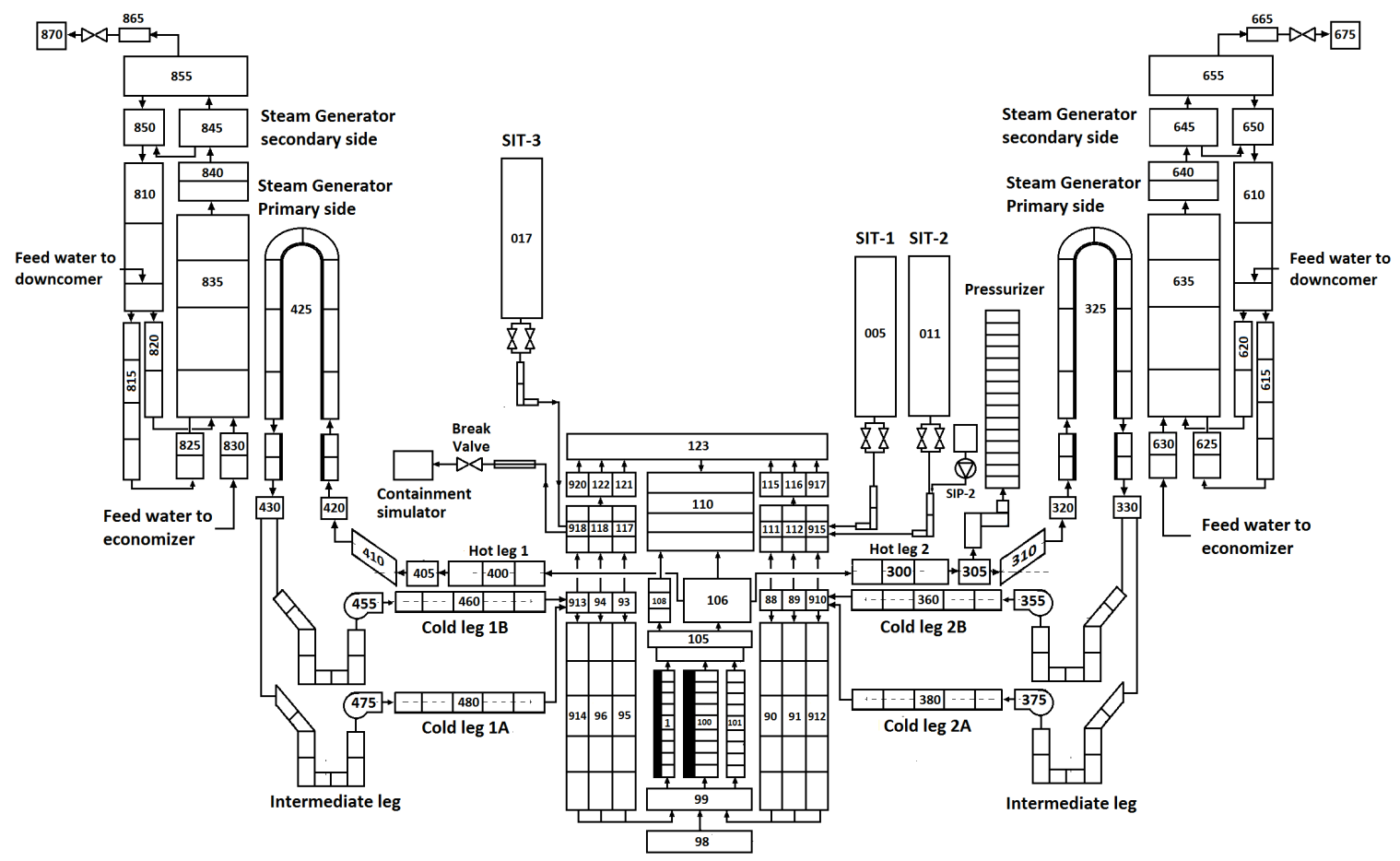

Figure 3. ATLAS test facility nodalization using RELAP5 for best estimate simulation 
According to the experimental sequences, the DVI line break was initiated by opening a trip valve after $1000 \mathrm{sec}$ steady-state simulation. The discharged fluid decrease the primary pressure as indicated in the pressurizer from $15.5 \mathrm{MPa}$ into a specific value of $10.72 \mathrm{MPa}$ for the low pressure (LPP) signal generation. This signal initiated several actuation measures with different delay times such as heater trip, main primary pumps trip, isolation of main steam and main feedwater lines, and actuation of one safety injection pump (SIP-2). When the downcomer pressure was lower than 4.03 $\mathrm{MPa}, 3$ safety injection tanks (SITs) started to inject water into the reactor pressure vessel (RPV) with high flow and low flow modes. As the core heater trips, the generated heat starts to decrease according to specific trend to simulate the core decay. Table 1 shows the latest time sequences obtained from the simulation after opening the break valve including its comparison with TRACE [24] and CATHARE codes [18].

Table 1. Comparison of sequence of the $50 \%$ DVI line break between experimental data and codes calculation

\begin{tabular}{|c|c|c|c|c|}
\hline Event & $\begin{array}{l}\text { Experiment } \\
(\mathrm{sec})[18]\end{array}$ & $\begin{array}{l}\text { RELAP5 } \\
\text { (sec) [present } \\
\text { study] }\end{array}$ & $\begin{array}{l}\text { TRACE } \\
(\sec )[24]\end{array}$ & $\begin{array}{l}\text { CATHARE } \\
(\mathrm{sec})[18]\end{array}$ \\
\hline Break valve open & 0.0 & 0.0 & 0.0 & 0.0 \\
\hline SG-1 safety valve to open & 24.5 & 36.5 & 41.1 & No data \\
\hline SG-2 safety valve to open & 24.5 & 36.7 & 41.1 & No data \\
\hline $\begin{array}{l}\text { Low pressurizer pressure for trip } \\
\text { signal }(<10,72 \mathrm{MPa})\end{array}$ & 25.0 & 32.02 & 38.08 & 29.1 \\
\hline Primary pump trip & 25.0 & 33.79 & 38.08 & 30.1 \\
\hline Turbine trip (main steam isolation) & 25.0 & 33.5 & 38.08 & 30.1 \\
\hline Feed water isolation & 32.0 & 41.07 & 44.09 & 37.1 \\
\hline Core power decay & 32.0 & 37.0 & No data & No data \\
\hline SIP-2 actuation & 54.0 & 61.72 & 66.14 & 57.6 \\
\hline $\begin{array}{l}\text { SIT injection from low downcomer } \\
\text { pressure }(<4,03 \mathrm{MPa}) \\
\text { Loop seal clearing }\end{array}$ & 468.0 & 452.9 & 435.89 & 460.9 \\
\hline Cold leg 1A & 189.0 & 375.0 & 423.0 & $\sim 1400.0$ \\
\hline Cold leg 1B & 189.0 & 375.75 & 423.0 & $\sim 1400.0$ \\
\hline Cold leg 2A & Not occured & 359.0 & Not occured & $\sim 160.0$ \\
\hline Cold leg 2B & 1230.0 & 376.0 & Not occured & $\sim 160.0$ \\
\hline Low flow from SITs & Not occured & Not occured & Not occured & Not occured \\
\hline End of simulation & 2933.0 & 3000.0 & 3300.0 & 3000.0 \\
\hline
\end{tabular}

Table 1 shows that there are still good agreements of the event chronology between the RELAP5 calculation with the experimental sequences. The differences in the timing of each sequence still existed and may be unavoided due to uncertainties in the transient measurements and the ATLAS modelling as also showed by TRACE and CATHARE codes. The timing of the trips were affected by the achievement of low pressurizer pressure signal as the time discrepancy calculated by the codes ranges from 4 to 13 seconds with the experimental data. After the break, the cooling of the primary system was decreased due to the loss of primary inventory causing the secondary pressure to increase. The opening of the steam generator safety valves will occur as the secondary pressure achieves the opening setpoint of $8.1 \mathrm{MPa}$. In the code calculations, the steam generator safety valves open after the low pressurizer pressure for trip signal, which is different with the experimental data. The cause could be due to the underestimation in the heat removal from the primary side or due to inaccurate safety valves capacity or steam header model. The occurrences of loop seal clearing are hardly observed in the RELAP5 calculation as the water level in the vertical intermediate legs before the main pumps is dropped into the horizontal legs. The phenomena is estimated to take place 350 seconds after the break, which is much different than the experimental 
data as also occurred in the two other codes. The low flow of SITs for all code calculations does not take place in agreement with the experimental data as its decreasing is slowed down by the operation of the SIP-2 until the end of experiment.

The transients of break flow between the RELAP5 calculation and experimental data are illustrated in Figure 4. The inital mass flow from the code is around $9 \mathrm{~kg} / \mathrm{sec}$ compared with experimental data of $6 \mathrm{~kg} / \mathrm{sec}$. The break mass flow rate by the code is therefore slightly overpredicted as a result of loss coefficient adjustment in the break pipe. In the experiment, a subcooled break flow was recorded in the early time, and then soon changed into saturated twophase flow. After a short period, it is converted to a single-phase water vapor (water in a gas phase) flow until the remaining experiment. In the code calculation, the peak mass value indicates a subcooled water break flow as characterized by the volume liquid fraction of 1.0 in the left vertical axis for 44 seconds. After that, a change into liquid fraction less than 1.0 is occured indicating a start of two-phase break flow with a decreasing rate. After 260 seconds, the single-phase water vapor flow is observed as the liquid fraction approaching the 0.0 value. Around 750 second after the break, a two phase flow with a low liquid fraction is observed due to the injected water from the injection pump and SITs to fill the upper downcomer and quickly discharged with the break flow.

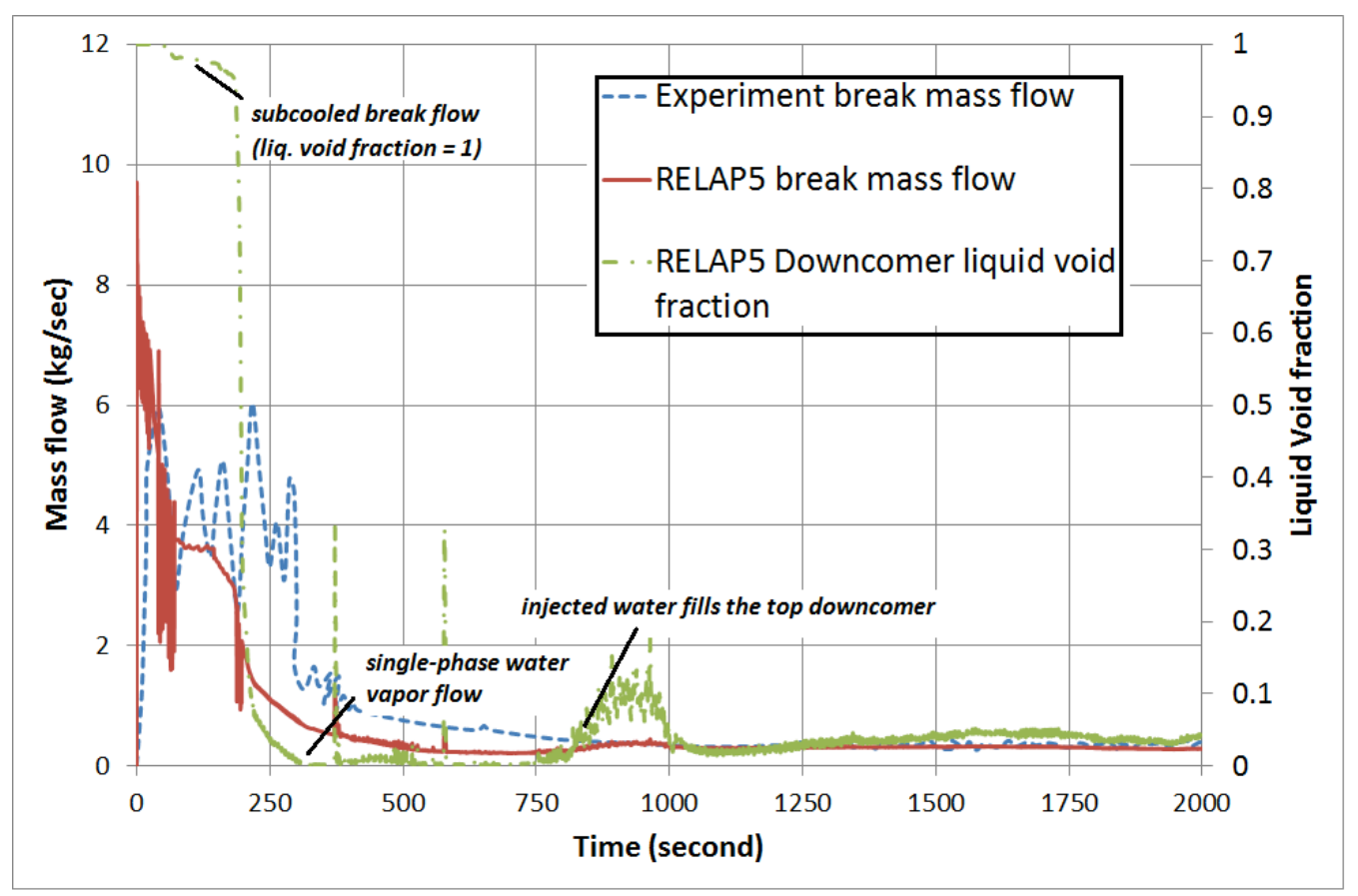

Figure 4. Transient of break mass flow rate between experiment and RELAP5

The comparison of primary pressure transients between the RELAP5 calculation and experimental data are illustrated in Figure 5. The decreases of primary pressure in the pressurizer are relatively in a good agreement in the early period of fast depressurization from $15.5 \mathrm{MPa}$ and after reaching the plateau region as the safety injection pump (SIP) starts to inject water inventory into the downcomer and when it approaches the secondary pressure value of 8.2 $\mathrm{MPa}$. This value approaches the setting value of $8.1 \mathrm{MPa}$ for opening the steam generator safety valve to open. After that, the primary pressure calculated by the code decreases again into a more stable value after 450 seconds to follow the core decay heat and injected water inventory, which is slighly different with the experiment. Between that period, a discrepancy is clearly observed between the code and experimental data, which will be later explained. 


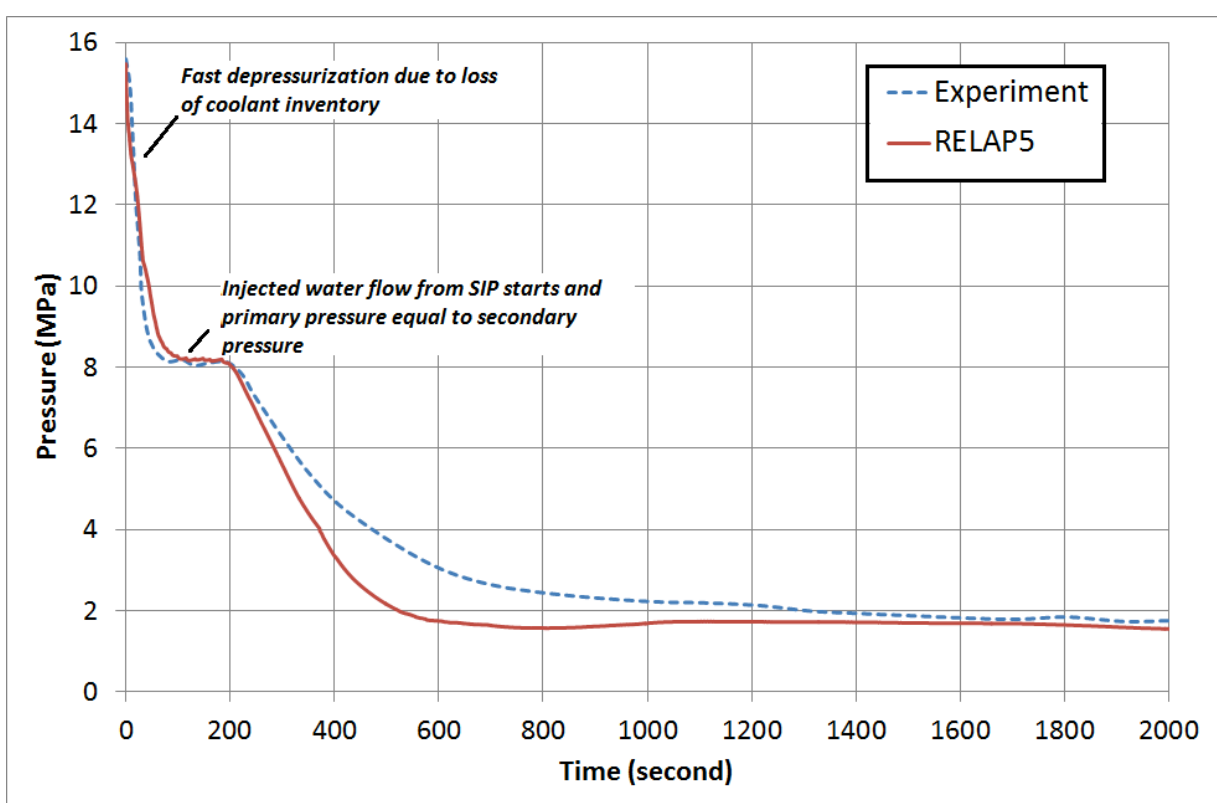

Figure 5. Transient of primary pressure between experiment and RELAP5

The comparison of transients of core water level between the RELAP5 calculation and experimental data are showed in Figure 6. The core water level in the RELAP5 is calculated by collapsing liquid level or the sum of all liquid void fractions in the core segments. After the break, the water level in the core continuously decreases to a minimum value of $1.5 \mathrm{~m}$, which is below the upper part of the active heater rods. The actuation of SIP to inject the water in to the downcomer did not affect the core water level depression due to the loop seal occurrences. The timing for reaching the minimum value in the code calculation is much longer than in the experimental data. The time as the core is refilled again is coincident with the time of the loop seal clearing on all of the intermediate legs. This phenomena shows that a correct prediction of the loop seal clearing will affect the time prediction of the core refilling. Both the experiment data and the code calculation show an increase of the core water level below the upper part of the core mainly after the injected water from the SITs starts to refill the core. The RELAP5 calculates a higher core water level than the experiment, which is explained later. The influence of core uncovery is explained in the prediction of peak heater cladding temperature showed in Figure 7.

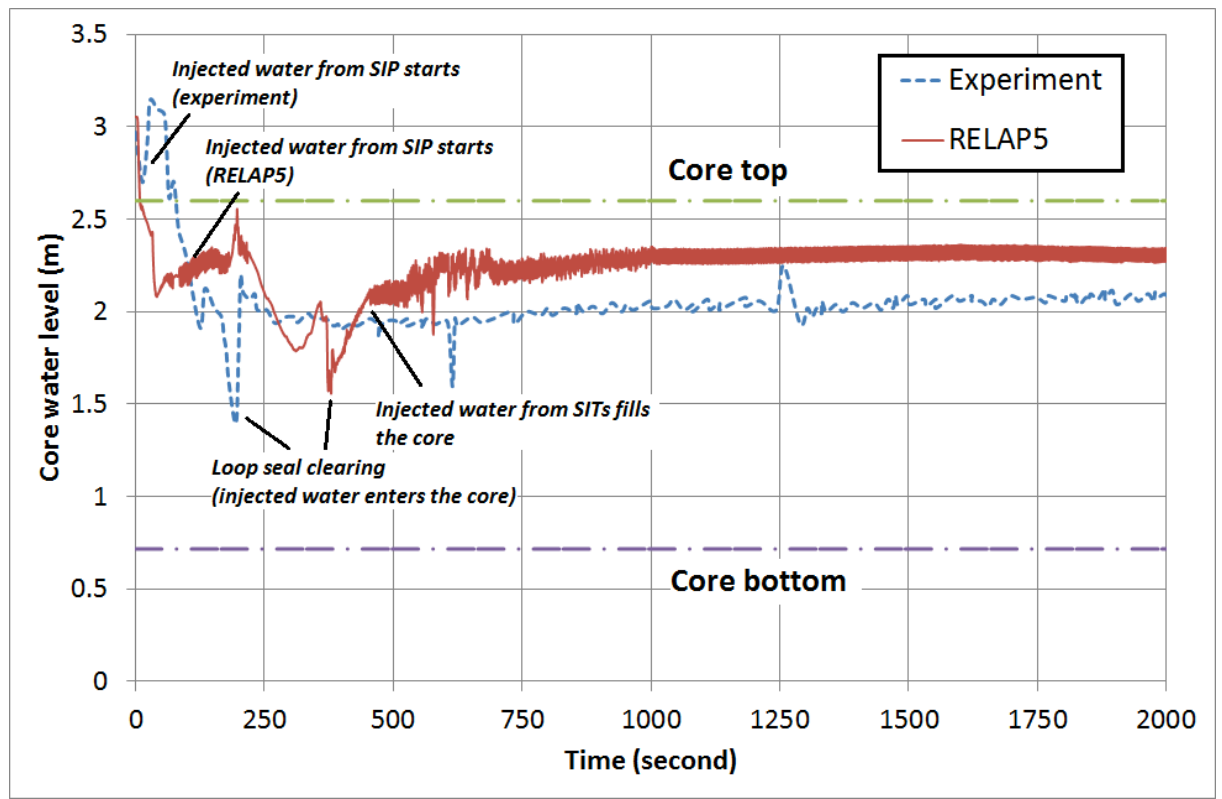

Figure 6. Transient of core water level between experiment and RELAP5 
Figure 7 illustrates the comparison of transients of maximum heater cladding temperature between the RELAP5 calculation and experimental data. Both of the RELAP5 calculation result and experimental data show a small increase in the peak cladding temperature (PCT) at the time when the core water level approaches its lowest level. The trend of the PCT for both data is in good agreement in the early period to achieve a plateau region. After that a fast decrease of PCTs is observed with the lower value of the RELAP5 calculation than the experimental data to approach a stable value. The discrepancy can be explained as follow by comparing the other transients and calculation data. One of possible cause is the accumulated safety injection flow from the SITs, which is slightly larger than the experiment. This difference in the injected flow has influence in the core water level after refilling as showed in Figure 6 as the RELAP5 calculated water level is higher than the experimental data. Those phenomena also affects the trend of the primary pressure decrease, which is also low as illustrated in Figure 5. One method to evaluate the discrepancy between the code calculation and the experimental data is to perform the uncertainty analysis, which is to be described below.

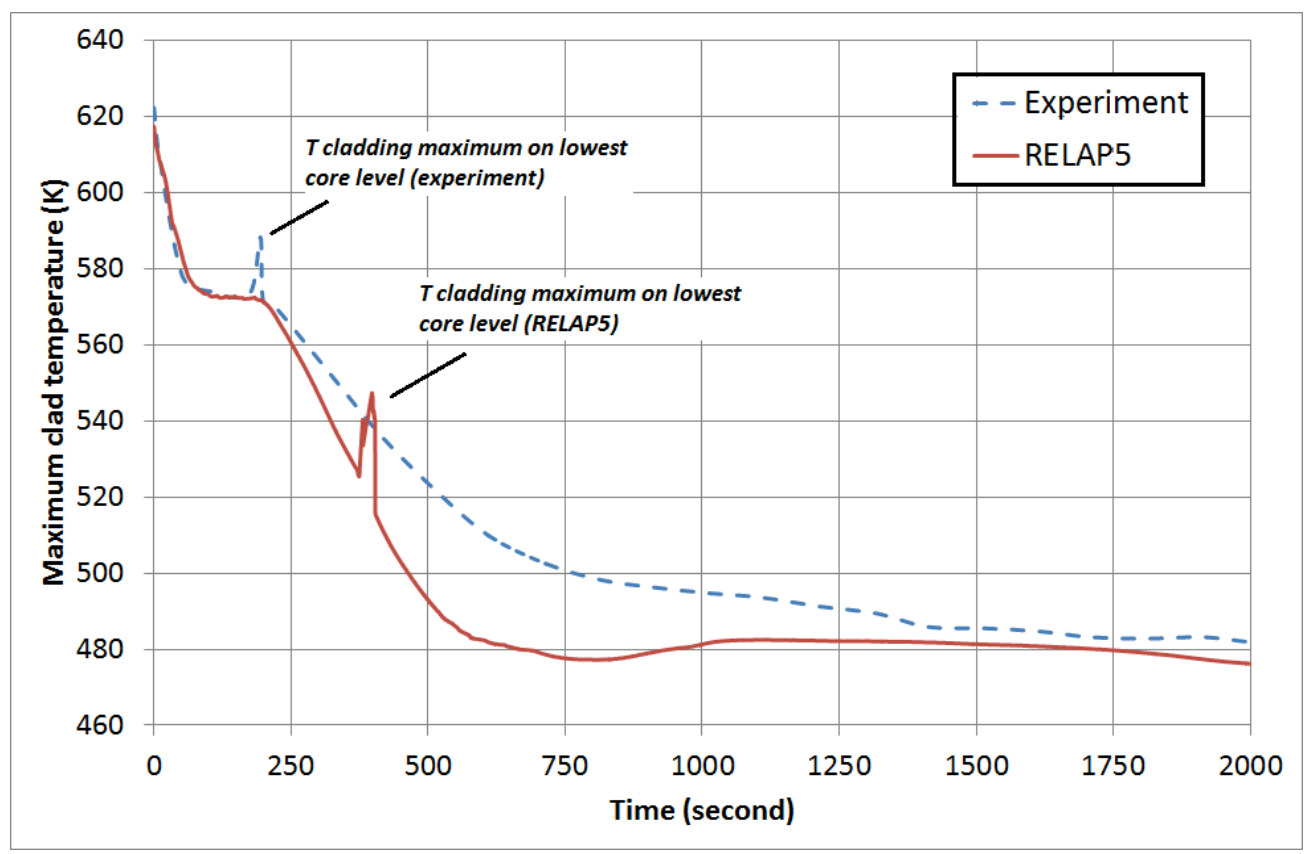

Figure 7. Transient of heater clad temperature between experiment and RELAP5

\section{PIRT for uncertainty parameters}

This section describes the third step of the uncertainty analysis methodology, with the aims are to identify and make ranking of important phenomena related to the event to select potential important parameters using the phenomena and identification ranking table (PIRT) approach. The $50 \%$ break of DVI line event is considered as the SBLOCA event, therefore that event should be used as a reference for determining the phenomena in the PIRT approach. M.J. Griffith et al [25] provided a desciption related to the important phenomena in the SBLOCA obtained by the PIRT method. The phenomena related to the SBLOCA phases takes place in several reactor components such as fuel rods, reactor core, vessel upper head, vessel upper plenum, hot legs, pressurizer and surge line, steam generator, cross-over piping, reactor coolant pumps, accumulator tank, cold legs, safety injection, vessel downcomer and lower plenum, break, and primary loop. From all phenomena identified above, several are selected having medium or highest impact on the peak cladding temperature (PCT) and suitable with the ATLAS model. For each phenomenon, important parameters are assigned, each with a type of probability density function (PDF). Table 2 contains several important parameters selected so far related to the SBLOCA phenomena and their PDF 
types obtained from references $[20,22]$. The mean value is associated with the input value used in the best estimate simulation, whereas the related range value is calculated from the referenced range value of typical PDF.

Table 2. Important parameters and their uncertainty range for uncertainty simulation

\begin{tabular}{|c|c|c|c|c|}
\hline Phenomena & Parameter & $\begin{array}{l}\text { PDF } \\
\text { Distribution }\end{array}$ & Mean & Range $\pm 1.96 \sigma$ \\
\hline $\begin{array}{l}\text { Fuel thermal behaviour } \\
\text { during all phases }\end{array}$ & $\begin{array}{l}\text { Decay heat factor } \\
\text { Hot local power peaking } \\
\text { factor }\end{array}$ & $\begin{array}{l}\text { normal } \\
\text { normal }\end{array}$ & $\begin{array}{l}1 \\
1\end{array}$ & $\begin{array}{l}0.934-1.066 \\
0.934-1.066\end{array}$ \\
\hline \multirow{5}{*}{$\begin{array}{l}\text { Flow rate at the break } \\
\text { during blowdown phase } \\
\text { Refilling during core } \\
\text { recovery phase }\end{array}$} & $\begin{array}{l}\text { Break discharge } \\
\text { coefficient }\end{array}$ & uniform & 0.82 & $0.602-1.038$ \\
\hline & SIT loss coefficient & normal & 18 & $10.8-25.2$ \\
\hline & SIT water temperature & uniform & $323.5(\mathrm{~K})$ & $309.61-337.39$ \\
\hline & SIP water temperature & uniform & $321.3(\mathrm{~K})$ & $301.91-340.69$ \\
\hline & SIT actuation pressure & normal & $4.03(\mathrm{MPa})$ & $3.815-4.245$ \\
\hline $\begin{array}{l}\text { Stored energy before the } \\
\text { break }\end{array}$ & $\begin{array}{l}\text { Fuel thermal } \\
\text { conductivity factor }\end{array}$ & uniform & 1 & $0.847-1.153$ \\
\hline
\end{tabular}

The mean and range values of Table 2 above will be used to generate a total of 100 random values according to each PDF distribution obtained from the Microsoft EXCEL. Each of those 100 random values were then inserted into 100 input files of ATLAS model according to the specific input parameters. For instance, a random value of decay heat factor will be used to recalculate the decay heat power versus time on each input file.

\section{Estimation of uncertainty bands}

Those 100 input files were then ran using RELAP5 to obtain the desired output parameters. Related to the SBLOCA simulation, the transient of PCT is considered important as output parameter for representing safety margin. The transient of primary pressure is also added for output parameter to evaluate the influence of random parameters. From a total number of 100 input files containing the random values of important parameters, 95 input files were successfully solved and 5 files were failed. Those 95 succesfully code runs are sufficient to apply the Wilk's formula with confidence level more than 0.95 . From the 95 output parameters obtained, a minimum and maximum value for each time segment were selected to represent the lower and upper uncertainty bands as illustrated on Figure 8 for the PCT time trend and Figure 9 for the primary pressure time trend. 


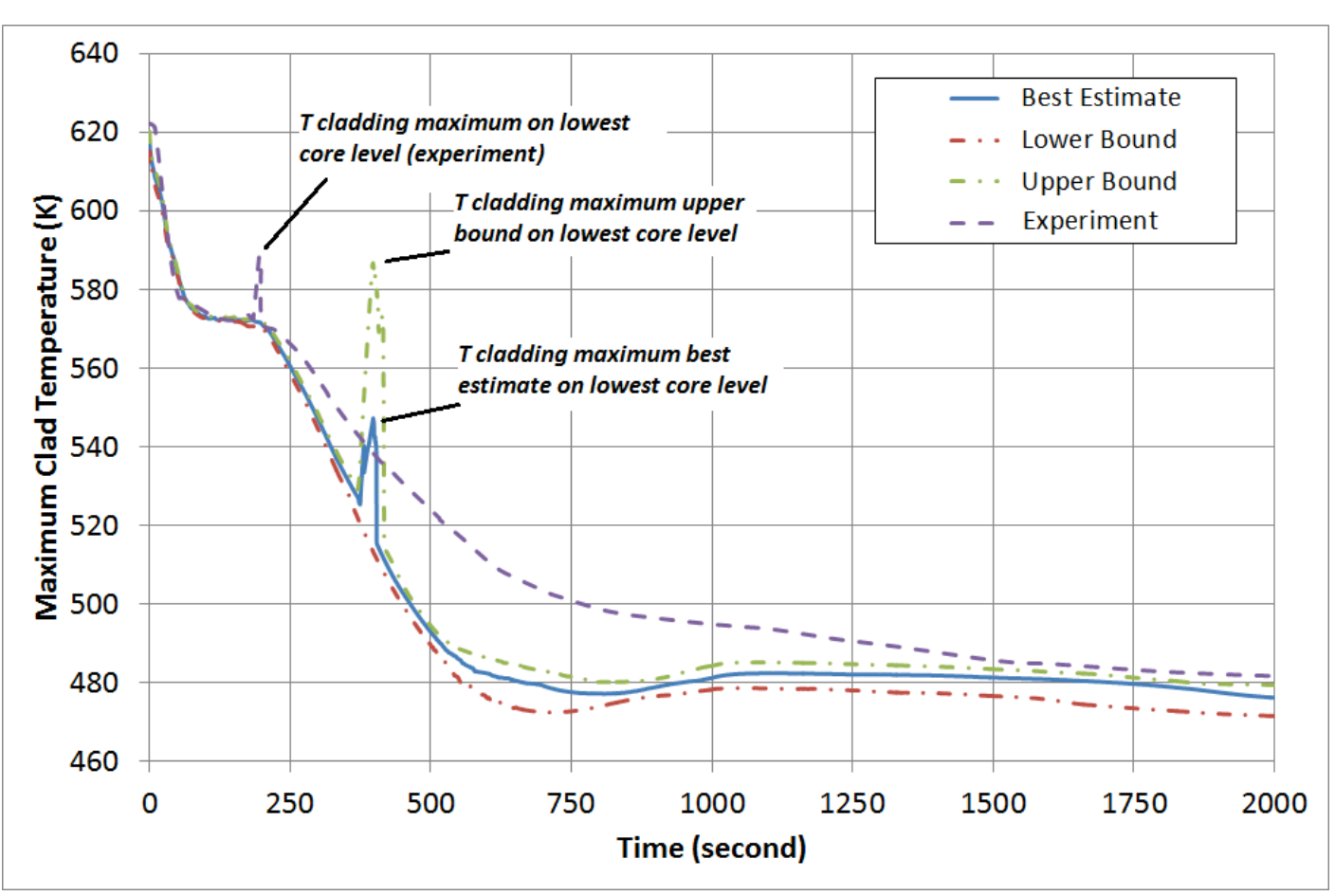

Figure 8. Uncertainty bands of ATLAS maximum heater clad temperature

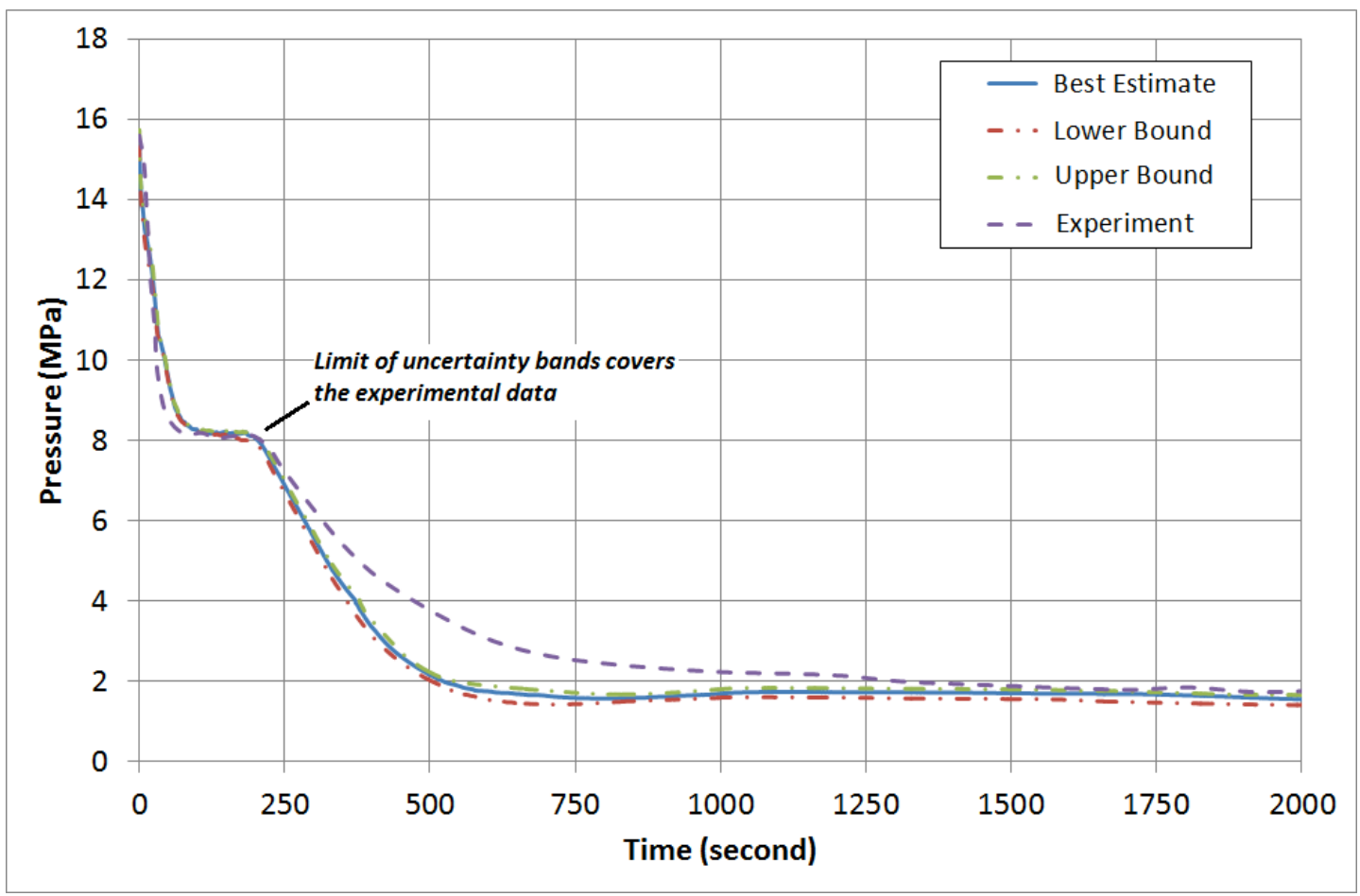

Figure 9. Uncertainty bands of ATLAS primary pressure

From Figure 8, the uncertainty bands simulated by RELAP5 are only in a close agreement with the experimental data in the earlier period (less than 250 seconds) of the transient. Beyond that time, the experimental PCTs are outside the calculated uncertainty bands. An interesting phenomena comes out in the simulation of PCT in the upper bound, since this value is calculated by taking the highest calculated values of all calculations. The calculated PCT in the upper bound appears in the identical point, where the core water level is on its lowest level, which is occurred later than the experiment as also noted in the best estimate simulation. The calculated PCT of 590 $\mathrm{K}$ in the upper bound is also close to the experimental data, which shows that the PCT value from 
the experiment is already inside the uncertainty bands of the calculation. A similar outcome is also visible in the uncertainty bands of primary pressure on Figure 9 . The uncertainty bands are not wide around the best estimate result due to minor influence of the selected important parameters to the primary pressure. From the previous discussion of the best estimate results, a modified model of the SIT injection line might be needed in order to obtain a closer result with the experiment. Other consideration might be also focused on the model of the upper plenum to simulate the lower core water level than the best estimate simulation. The lower core water level will cause an increase in the maximum PCT in the decreasing trend to a better agreement with the experimental data, because a small discrepancy in the core water level will cause a large difference in the maximum PCT [15]. After the best estimate results are improved, a carefully selection of the important phenomena should be carried out by the analyst. In the ATLAS uncertainty simulation, additional randomly generated important parameters might be needed by referring the ROSA uncertainty analysis $[15,26]$ in order to obtain wider uncertainty bands.

From the above results obtained, all key aspects of the BEPU process using the GRS methodology have been presented by selecting the ATLAS facility. The process started from the best estimate simulation and analysis to know the most important safety parameters to be selected based on the safety criteria of the selected initiating event and its comparison with the experimental results. The next step was to identify and rank important phenomenas to select potential important parameters achieved using the PIRT approach, in which each selected important parameters was associated with an appropriate PDF. After that, a number of random sampling of selected parameters was generated, representing the number of computer simulation performed by RELAP5. After all results are obtained, the uncertainty bands are estimated for the selected safety parameters. Therefore all key aspects of the GRS methodology in particular have been clearly described and applied in this study. It is possible to perform the uncertainty analysis as a supplement of the best estimate analysis in order to gain more accurate results of the deterministic safety analysis.

\section{CONCLUSIONS}

A best estimate plus uncertainty (BEPU) analysis of the ATLAS facility in the $50 \%$ DVI line break event have been carried out using the RELAP5 as the best estimate code and GRS uncertainty approach. Some key aspects of the BEPU process using the GRS methodology have been outlined during the process in order to obtain the full understanding regarding the quantification of uncertainty in the modelling. One of interesting point is that the calculated peak cladding temperature (PCT) in the upper bound calculation is close to the experimental data of 590 $\mathrm{K}$, even though the timing is different. Therefore, the uncertainty bands only cover the occurrence of the PCT and in overall they are only in a close agreement with the experimental data in the earlier period of the transient. Based on the results obtained, the overall accuracy of the best estimate simulation plays a key role on the final results of the uncertainty analysis because the propagation of any discrepancy in the best estimate with the experimental data will occur throughout the simulation. After that, a carefully selection of the important parameters to be randomly generated should be done to get more representative results of the uncertainty bands. So far, the GRS uncertainty approach is the easiest approach, that can be used in the BEPU analysis for any analyst who has interest in the uncertainty evaluation of the deterministic analysis.

\section{ACKNOWLEDGEMENT}

The authors gratefully acknowledge the Center for Nuclear Reactor Safety and Technology (PTKRN) for supporting this research. This research was fully supported by the BATAN Research Project (DIPA) of the year 2016. 


\section{REFERENCES}

1. IAEA Best Estimate Safety Analysis For Nuclear Power Plants: Uncertainty Evaluation. Safety Reports Series No. 52. Vienna, Austria: International Atomic Energy Agency; 2008.

2. IAEA Safety Margins of Operating Reactors: Analysis of uncertainties and implications for Decision Making. IAEA-TECDOC-1332. Vienna, Austria: International Atomic Energy Agency; 2003.

3. Reocreux M. Safety analysis and best estimate codes. in: the 4th Regional Meeting of Nuclear Energy in Central Europe, Bled, Slovenia. 1997.

4. Wilson GE. Historical insights in the development of best estimate plus uncertainty safety analysis. Ann. Nucl. Energy. 2013; 52: 2 - 9 .

5. D'Auria F., Mazzantini O. The best estimate plus uncertainty challenge in the current licensing process of present reactors. Sci. Technol. Nucl. Ins. 2011; ID 958218. doi: $10.1155 / 2011 / 958218$.

6. D'Auria F., Camargo C., Mazzantini O. The best estimate plus uncertainty (BEPU) approach in licensing of current nuclear reactors. Nucl. Eng. Des. 2012; 248: $317-328$.

7. Blake L., Gavrus G., Vecchiarelli J. Best estimate plus uncertainty analysis of LBLOCA for a pickering B CANDU reactor. in: ASME 2010 3rd Joint US-European Fluids Engineering Summer Meeting, Quebec, Canada. 2010.

8. Reventos F. Major results of the OECD BEMUSE (best estimate methods, uncertainty and sensitivity evaluation) programme. in: The Seminar on The Transfer of Competence, Knowledge and Experience Gained Through CSNI Activities in The Field of ThermalHydraulics (THICKET), Pisa, Italy. 2008.

9. De Crecy A., Bazin P., Glaeser H., Skorek T., Joucla J., Probst P et al. Uncertainty and sensitivity analysis of the LOFT L2-5 test: results of the BEMUSE programme. Nucl. Eng. Des. 2008; 238: $3561-3578$.

10. Perez M., Reventos F., Batet L., Guba A., Toth I., Mieusset T et al. Uncertainty and sensitivity analysis of a LBLOCA in a PWR nuclear power plant: results of the phase V of the BEMUSE programme. Nucl. Eng. Des. 2011; 241: $4206-4222$.

11. Munoz-Cobo JL., Escriva A., Mendizabal R., Pelayo F., Melara J. CSAU methodology and results for an ATWS event in a BWR using Information Theory Methods. Nucl. Eng. Des. 2014; 278: 445 - 464.

12. Glaeser H. GRS method for uncertainty and sensitivity evaluation of code results and applications. Sci. Technol. Nucl. Ins. 2008; ID 798901. doi:10.1155/2008/798901.

13. D'Auria F., Giannotti W. Development of code with capability of internal assessment of uncertainty. Journal Nucl. Tech. 2000; 131 (1): $159-196$.

14. Glaeser H. Results from the application of uncertainty methods in the CSNI uncertainty methods study (UMS). in: The Seminar on The Transfer of Competence, Knowledge and Experience Gained Through CSNI Activities in The Field of Thermal-Hydraulics (THICKET), Pisa, Italy. 2008.

15. Freixa J., Kim TW., Manera A. Thermal-hydraulic analysis of an intermediate LOCA test at the ROSA facility including uncertainty evaluation. Nucl. Eng. Des. 2012; 249: $97-103$.

16. Ekariansyah AS., Widodo S. Performance analysis of AP1000 passive systems during Direct Vessel Injection (DVI) line break. Atom Indonesia. 2016; 42: 79 - 88.

17. Widodo S., Ekariansyah AS. AP 1000 partial and complete loss of flow accident analysis using RELAP5. in: Seminar Nasional Teknologi Energi Nuklir. Batam. 2016 (in Indonesian).

18. NEA International Standard Problem No. 50, ATLAS Test, SB-DVI-09:50\% (6-inch) Break of DVI line of the APR1400 - Final Integration Report, NEA/CSNI/R(2012)6, Korea: Korea Atomic Energy Research Institute; 2012. 
19. Kim YS., Choi KY., Park HS., Cho S., Kim BD., Choi NH., Baek WP. Commissioning of the ATLAS thermal-hydraulic integral test facility. Ann. Nucl. Energy. 2008; 35: $1791-1799$.

20. Perez M., Reventos F. Integrated uncertainty analysis using RELAP/SCDAPSIM/Mod4.0. in: the 7th International Topical Meeting on Nuclear Reactor Thermal Hydraulics, Operation, and Safety (NUTHOS-7), Seoul. 2008.

21. Aksan N. International standard problems and small break loss of coolant accident (SBLOCA). Sci. Technol. Nucl. Ins. 2008; ID 814572. doi: 10.1155/2008/814572.

22. Lee SW., Chung BD., Bang YS., Bae SW.. Analysis of uncertainty quantification method by comparing Monte-Carlo method and Wilk's formula. Nucl. Eng. Tech. 2014; 46. doi: 10.5516/NET.02.2013.047.

23. Ekariansyah AS., Widodo S., Tjahjono H. Modelling on the ATLAS test facility for best-estimate simulation of loss of coolant accident. in: Seminar Nasional Teknologi Energi Nuklir, Batam. 2016 (in Indonesian).

24. Veronese F., Kozlowsk T. TRACE V5 code applicatio DVI line break LOCA using ATLAS facility. Nucl. Eng. Tech. 2012; 44: $719-726$.

25. Griffith MJ., Schlegel JP., Hibiki T., Ishii M., Kinoshita I., Yoshida Y. Phenomena identification and ranking table for thermal-hydraulic phenomena during small-break LOCA with loss of high pressure injection. Prog. Nucl. Energ. 2014; 73: $51-63$.

26. Freixa J., Kim TW., Manera A. Post-test thermal-hydraulic analysis of two intermediate LOCA tests at the ROSA facility including uncertainty evaluation. Nucl. Eng. Des. 2013; 264: $153-160$. 